\title{
Efecto de la Suplementación con Harina de Yacón o Aceite de Copaiba sobre el Comportamiento Productivo e Integridad Intes- tinal de Pollos Inoculados con Coccidias
}

\author{
Effect of Supplementation with Dietary Yacon Meal or Copaiba Oil on Broiler \\ Performance and Intestinal Integrity of Brollers Inoculated with Coccidia
}

Gardenia Tupayachi S. ${ }^{1}$, Otto Zea M. ${ }^{1}$, Carlos Vílchez P. ${ }^{1,2}$

\section{Resumen}

El estudio tuvo por objetivo evaluar el efecto de la suplementación de harina de yacón (Smallanthus sonchifolius) y de aceite de copaiba en el comportamiento productivo y morfometría intestinal en pollos de 1 a 21 días de edad y desafiados con coccidias (Eimeria) a los 14 días de edad. Se emplearon 120 pollos BB machos de la Línea Cobb 500, distribuidos en cuatro tratamientos con tres repeticiones y 10 animales por repetición: $\mathrm{T} 1$, dieta basal ( in coccidiostato); T2 dieta basal + coccidiostato; T3 dieta basal + harina de yacón $(0.25 \%)$ y T4 dieta basal + aceite de copaiba $(0.15 \mathrm{ml} / \mathrm{kg})$. Al final del ensayo se sacrificaron 6 aves por tratamiento y se tomaron muestras de intestino delgado para medir la altura de vellosidad, profundidad de cripta, número de células caliciformes y relación altura de vellosidad/profundidad de cripta. Asimismo, se hizo el recuento de ooquistes/g de heces. No se encontró diferencia estadística en ganancia de peso, consumo de alimento ni en conversión alimenticia. Tampoco se encontró diferencia estadística para la altura de vellosidades. Aves tratadas con aceite de copaiba (T4) presentaron mayor profundidad de cripta en duodeno y menor número de células calciformes en íleon $(\mathrm{p}<0.05)$. No hubo diferencias estadísticas en el recuento de ooquistes. La suplementación con aceite de copaiba mostró tener un efecto sobre la regeneración celular a nivel intestinal en pollos infectados experimentalmente con Eimeria.

Palabras clave: pollos de carne, coccidias, integridad intestinal, aceite de copaiba, harina de yacón

\footnotetext{
${ }^{1}$ Departamento Académico de Nutrición, Facultad de Zootecnia, Universidad Nacional Agraria La Molina, Lima, Perú

${ }^{2}$ E-mail: cvilchezp@lamolina.edu.pe
}

Recibido: 16 de enero de 2016

Aceptado para publicación: 9 de mayo de 2016 
This study aimed to evaluate the effect of yacon (Smallanthus sonchifolius) flour and copaiba oil on the productive performance and intestinal integrity in broilers from 1 to 21 days of age which were challenged with Eimeria on day 14. One-day old Cobb 500 male chicks $(\mathrm{n}=120)$ were randomly distributed into four groups, using three replicates and 10 birds per replicate. The treatments were: T1, basal diet without coccidiostat (negative control); T2, basal diet containing coccidiostat (positive control); T3, as T1 + yacon flour $(0.25 \%) ; \mathrm{T} 4$, as $\mathrm{T} 1+$ copaiba oil $(0.15 \mathrm{ml} / \mathrm{kg})$. Six birds were slaughtered at the end of the trial and gut samples were collected to measure villus height, crypt depth, number of caliciform cells and the rate villus height/crypt depth. Also, the number of oocysts/g of faeces was evaluated. No significant differences were found between treatments on body weight gain, feed intake and feed conversion. In addition, no significant difference was found on villus height. Chicks treated with copaiba oil (T4) showed larger crypt depth in duodenum and lowest number of calciform cells in ileum $(p<0.05)$. No statistical difference was found in relation to oocyst counts. Supplementation with copaiba oil showed positive effects on cellular regeneration in the intestine in chickens experimentally infected with Eimeria.

Key words: broilers, coccidia, intestinal integrity, copaiba oil, yacon flour

\section{INTRODUCCIÓN}

La eimeriosis es una enfermedad causada por un protozoario del género Eimeria y es una de las principales causas de las pérdidas económicas en la avicultura. La incidencia crónica de esta enfermedad produce retardo del crecimiento, pobre conversión alimenticia y alta morbilidad, además de pérdidas directas por mortalidad en los diversos sistemas de producción avícola (Adams et al., 1996). Para contrarrestar un cuadro de coccidiosis es necesaria la administración de anticoccidiales que permita controlar los síntomas de la enfermedad. Sin embargo, el uso indiscriminado de estos fármacos puede generar resistencia a mediano plazo a dichas enfermedades en aves. Así, por ejemplo, Zahid (2008) observó que Eimeria tenella era resistente al anticoccidiostato salinomicin y resistencia intermedia a otros como la sulfoquinoxalina, clopidol y diclazuril. Ante esta situación, se ha incrementado la prohibición del uso de tales fármacos en el mundo (Farrant, 2001).
Una alternativa al uso de coccidiostatos son productos naturales como los prebióticos $\mathrm{y}$ aceites esenciales, los cuales tienen propiedades particulares que mejoran la salud intestinal, disminuyendo la carga microbiana en el tracto gastrointestinal, cumpliendo así un efecto promotor de crecimiento similar a los obtenidos con antibióticos (Martínez, 2012). Al respecto, existen datos de investigación que muestran que el uso de harina de yacón (Smallanthus sonchifolius) (Gonzales, 2009) y el aceite de copaiba (Santos et al., 2008), una resina obtenida de árboles de género Copaifera, cumplen efectos benéficos en el tracto intestinal, favoreciendo el crecimiento de las vellosidades intestinales y a través de su actividad antimicrobiana, respectivamente (Santos et al., 2008; Arroyo et al., 2009). No obstante, no existe información acerca del uso de estos productos en cuadros de eimeriosis.

Basado en estas informaciones, el propósito del presente trabajo fue determinar la relación entre la harina de yacón y el aceite de copaiba dietaria sobre el comportamiento 
productivo y la morfometría intestinal de pollos desafiados con coccidias.

\section{Materiales y Métodos}

El estudio se llevó a cabo en el Laboratorio de Investigación en Nutrición y Alimentación de Aves (LINAA) de la Universidad Nacional Agraria de La Molina (UNALM), Lima, Perú. Se emplearon 120 pollos BB de la Línea Cobb 500, machos, de un día de edad. Las aves fueron distribuidas al azar en cuatro tratamientos $(n=30)$ con tres repeticiones por 10 pollos cada uno. El periodo de crianza fue de 21 días. Las aves estuvieron alojadas en dos jaulas metálicas de malla galvanizada (baterías), de cinco pisos cada una y con dos divisiones por piso, $\mathrm{y}$ con comederos y bebederos lineales tipo canaleta en la parte externa con cama de viruta.

Los tratamientos fueron: $\mathrm{T} 1$ dieta basal ( $\sin$ coccidiostato); T2 dieta basal + coccidiostato; T3 dieta basal + harina de yacón $(0.25 \%)$ y T4 dieta basal + aceite de copaiba $(0.15 \mathrm{ml} / \mathrm{kg})$. Las dietas experimentales fueron formuladas siguiendo las especificaciones nutricionales de la Línea Cobb 500 (Cobb-Vantress, 2002). La composición $\mathrm{y}$ valor nutricional de las dietas se muestran en los cuadros 1 y 2.

El ensayo se dividió en dos fases: la primera de 1 a 14 días de edad, suministrándose una dieta basal a base de maíz, soya y harina de pescado (15\%), y la segunda a partir del día 15 de edad, proporcionándose una dieta basal a base de maíz y soya. Ambas dietas fueron complementadas con aminoácidos sintéticos y suplementadas con una premezcla de vitaminas y minerales. El contenido de fructooligosacáridos de la harina de yacón se determinó en el laboratorio del Instituto de Biotecnología, UNALM.

El desafío coccidial se realizó el día 14 de edad, por vía oral, empleando cánulas oroingluviales de acceso al buche del ave
(Martínez, 2012). Se administró una dosis de un inóculo de coccidia preparado para contener ooquistes no atenuados provenientes de aislamientos de campo de E. acervulina, $E$. maxima, E. tenella, E. necatrix y E. brunetti, con una concentración total no menor de $24 \times 10^{5}$ ooquistes vivos por dosis, equivalente a 10 dosis de una vacuna comercial (Immucox for Chickens II, Vetech Laboratories).

Se realizaron mediciones semanales de peso vivo y consumo de alimento, utilizando una balanza digital de plataforma con precisión de $0.01 \mathrm{~g}$. A partir de estos datos se estimó la conversión alimenticia. Se sacrificaron seis animales por tratamiento al término del periodo de crianza (21 d) para evaluar la morfometría intestinal.

Para las mediciones citomorfométricas se colectaron tres segmentos de $2 \mathrm{~cm}$ cada uno del intestino delgado. El primer segmento se ubicó al inicio del duodeno (duodeno craneal), el segundo a $2 \mathrm{~cm}$ de la salida del colédoco (duodeno caudal) y el tercero correspondió al yeyuno, a $8 \mathrm{~cm}$ antes del divertículo de Meckel. Las muestras fueron guardadas y fijadas en formol al $10 \%$ y remitidas a la Universidad Cayetano Heredia, Lima, para su procesamiento histológico consistente en inclusión en parafina y los cortes coloreados con hematoxilina-eosina.

Las mediciones histológicas en las láminas se hicieron siguiendo una adaptación del protocolo utilizado por Batista de Olivera et al. (2000). En cada lámina se realizaron 30 mediciones de altura de vellosidad, profundidad de cripta y número de células caliciformes, usando un microscopio óptico con un ocular micrométrico. En las mediciones de altura de vellosidad y profundidad de cripta se usó el objetivo de 10x y para el contaje de células caliciformes el objetivo de 40x. El cálculo de las mediciones se realizó utilizando un factor de corrección, multiplicando el factor del objetivo (0.010) por el número de líneas que abarca el tamaño del ocular micrométrico por 1000 , dando el valor 
Cuadro 1. Composición porcentual y valor nutritivo de las dietas experimentales ${ }^{1}$ empleadas en la fase de 1 a 14 días

\begin{tabular}{|c|c|c|c|c|}
\hline & $\mathrm{T} 1$ & $\mathrm{~T} 2$ & $\mathrm{~T} 3$ & $\mathrm{~T} 4$ \\
\hline \multicolumn{5}{|l|}{ Composición } \\
\hline Maíz & 51.92 & 51.92 & 51.67 & 51.92 \\
\hline Torta de soya & 26.72 & 26.72 & 26.75 & 26.72 \\
\hline Aceite crudo soya & 2.82 & 2.82 & 2.83 & 2.82 \\
\hline Harina de pescado prime & 15.00 & 15.00 & 15.00 & 15.00 \\
\hline Fosfato bicálcico & 1.58 & 1.58 & 1.58 & 1.58 \\
\hline Carbonato de calcio & 0.66 & 0.66 & 0.66 & 0.66 \\
\hline Sal común & 0.39 & 0.39 & 0.39 & 0.39 \\
\hline Metionina DL & 0.24 & 0.24 & 0.24 & 0.24 \\
\hline Lisina HCL & 0.19 & 0.19 & 0.19 & 0.19 \\
\hline Pre mezcla 1 & 0.10 & 0.10 & 0.10 & 0.10 \\
\hline Cloruro colina $60 \%$ & 0.09 & 0.08 & 0.09 & 0.09 \\
\hline Secuestrante de micotoxinas & 0.09 & 0.09 & 0.09 & 0.09 \\
\hline Treonina L & 0.04 & 0.04 & 0.04 & 0.04 \\
\hline Zinc Bacitracina & 0.04 & 0.04 & 0.04 & 0.04 \\
\hline Arena & 0.04 & 0.00 & 0.04 & 0.04 \\
\hline Harina de yacón & -- & -- & 0.21 & -- \\
\hline Coccidiostato & -- & 0.04 & -- & -- \\
\hline Antifúngico & 0.04 & 0.04 & 0.04 & 0.04 \\
\hline Antioxidante & 0.04 & 0.04 & 0.04 & 0.04 \\
\hline Aceite de copaiba (ml) & -- & -- & -- & 15.00 \\
\hline \multicolumn{5}{|l|}{ Valor nutricional (calculado) } \\
\hline $\mathrm{EM}, \mathrm{Kca} / \mathrm{kg}$ & 2998.20 & 2998.20 & 2998.20 & 2998.20 \\
\hline Proteína cruda, $\%$ & 27.55 & 27.55 & 27.55 & 27.55 \\
\hline Lisina, $\%$ & 1.83 & 1.83 & 1.83 & 1.83 \\
\hline Metionina + cistina, $\%$ & 1.09 & 1.09 & 1.09 & 1.09 \\
\hline Treonina, $\%$ & 1.12 & 1.12 & 1.12 & 1.12 \\
\hline Triptófano, \% & 0.31 & 0.31 & 0.32 & 0.31 \\
\hline Calcio, $\%$ & 1.30 & 1.30 & 1.30 & 1.30 \\
\hline Fosforo disponible, $\%$ & 0.74 & 0.74 & 0.74 & 0.74 \\
\hline Sodio, $\%$ & 0.27 & 0.27 & 0.27 & 0.27 \\
\hline Grasa total, \% & 5.97 & 5.97 & 5.98 & 5.97 \\
\hline Fibra cruda, $\%$ & 2.26 & 2.26 & 2.26 & 2.26 \\
\hline
\end{tabular}

${ }^{1}$ T1: Grupo control (sin coccidiostato); T2: Grupo con coccidiostato; T3: Grupo con 0.25\% de harina de yacón (contenido de fructo-oligosacáridos: $37.45 \mathrm{~g}$ FOS/100 g de harina de yacón); T4: Grupo con $0.150 \mathrm{ml}$ de aceite de copaiba/kg de alimento 
Cuadro 2. Composición porcentual y valor nutritivo de las dietas experimentales ${ }^{1}$ empleadas en la fase de 15 a 21 días

\begin{tabular}{lcccc}
\hline & $\mathrm{T} 1$ & $\mathrm{~T} 2$ & $\mathrm{~T} 3$ & $\mathrm{~T} 4$ \\
\hline Composición & & & & \\
Maíz & 61.09 & 61.09 & 60.79 & 61.09 \\
Torta de soya & 31.44 & 31.44 & 31.47 & 31.44 \\
Aceite crudo soya & 3.32 & 3.32 & 3.33 & 3.315 \\
Harina de pescado prime & -- & -- & -- & - \\
Fosfato bicálcico & 1.86 & 1.86 & 1.86 & 1.86 \\
Carbonato de calcio & 0.77 & 0.77 & 0.77 & 0.77 \\
Sal común & 0.46 & 0.46 & 0.46 & 0.46 \\
Metionina DL & 0.28 & 0.28 & 0.28 & 0.28 \\
Lisina HCL & 0.22 & 0.22 & 0.22 & 0.22 \\
Pre mezcla & 0.12 & 0.12 & 0.12 & 0.12 \\
Cloruro Colina 60\% & 0.10 & 0.10 & 0.10 & 0.10 \\
Secuestrante de micotoxinas & 0.10 & 0.10 & 0.10 & 0.10 \\
Treonina L & 0.05 & 0.05 & 0.04 & 0.05 \\
Zinc Bacitracina & 0.05 & 0.05 & 0.05 & 0.05 \\
Arena & 0.05 & -- & 0.05 & 0.05 \\
Harina de yacón & -- & -- & 0.25 & - \\
Coccidiostato & - & 0.05 & -- & - \\
Antifúngico & 0.05 & 0.05 & 0.05 & 0.05 \\
Antioxidante & 0.05 & 0.05 & 0.05 & 0.05 \\
Aceite de copaiba (ml) & -- & -- & -- & 15.00 \\
Valor nutricional (calculado) & & & & \\
EM, Kcal/kg & 3072.00 & 3072.00 & 3072.00 & 3072.00 \\
Proteína cruda, \% & 20.50 & 20.50 & 20.50 & 20.50 \\
Lisina, \% & 1.26 & 1.26 & 1.26 & 1.26 \\
Metionina + cistina, \% & 0.94 & 0.94 & 0.94 & 0.94 \\
Treonina, \% & 0.82 & 0.82 & 0.82 & 0.82 \\
Triptófano, \% & 0.23 & 0.23 & 0.23 & 0.23 \\
Calcio, \% & 0.87 & 0.87 & 0.87 & 0.87 \\
Fosforo disponible, \% & 0.44 & 0.44 & 0.44 & 0.44 \\
Sodio, \% & 0.20 & 0.20 & 0.20 & 0.20 \\
Grasa total, \% & 6.15 & 6.15 & 6.15 & 6.15 \\
Fibra cruda, \% & 2.48 & 2.48 & 2.49 & 2.48 \\
\hline
\end{tabular}

${ }^{1} \mathrm{~T} 1$ : Grupo control (sin coccidiostato); T2: Grupo con coccidiostato; T3: Grupo con $0.25 \%$ de harina de yacón (contenido de fructo-oligosacáridos: $37.45 \mathrm{~g}$ FOS/100 g de harina de yacón); T4: Grupo con $0.150 \mathrm{ml}$ de aceite de copaiba/kg de alimento 
Cuadro 3. Efecto de la suplementación con harina de yacón y aceite de copaiba sobre el comportamiento productivo de pollos de carne en el periodo de 1 a 14 días de edad

\begin{tabular}{cccccc}
\hline Tratamientos $^{1}$ & $\begin{array}{c}\text { Peso inicial } \\
(\mathrm{g})\end{array}$ & $\begin{array}{c}\text { Peso final } \\
(\mathrm{g})\end{array}$ & $\begin{array}{c}\text { Ganancia de } \\
\text { peso } \\
(\mathrm{g} / \text { día })\end{array}$ & $\begin{array}{c}\text { Consumo de } \\
\text { alimento } \\
(\mathrm{g} / \text { día })\end{array}$ & $\begin{array}{c}\text { Conversión } \\
\text { alimenticia }\end{array}$ \\
\hline $\mathrm{T} 1$ & $44.9^{\mathrm{a}}$ & $539.7^{\mathrm{a}}$ & $35.4^{\mathrm{a}}$ & $50.0^{\mathrm{a}}$ & $1.41^{\mathrm{a}}$ \\
$\mathrm{T} 2$ & $44.4^{\mathrm{a}}$ & $553.5^{\mathrm{a}}$ & $36.4^{\mathrm{a}}$ & $50.7^{\mathrm{a}}$ & $1.39^{\mathrm{a}}$ \\
$\mathrm{T} 3$ & $44.2^{\mathrm{a}}$ & $554.5^{\mathrm{a}}$ & $36.5^{\mathrm{a}}$ & $50.5^{\mathrm{a}}$ & $1.39^{\mathrm{a}}$ \\
$\mathrm{T} 4$ & $44.0^{\mathrm{a}}$ & $544.5^{\mathrm{a}}$ & $35.8^{\mathrm{a}}$ & $49.8^{\mathrm{a}}$ & $1.39^{\mathrm{a}}$ \\
\hline
\end{tabular}

${ }^{1}$ T1: Grupo control (sin coccidiostato); T2: Grupo con coccidiostato; T3: Grupo con $0.25 \%$ de harina de yacón (contenido de fructo oligosacáridos: $37.45 \mathrm{~g} \mathrm{FOS} / 100 \mathrm{~g}$ de harina de yacón); T4: Grupo con $0.150 \mathrm{ml}$ de aceite de copaiba/kg de alimento

${ }^{a}$ Superíndice similar dentro de columnas indica ausencia de diferencia estadística

Cuadro 4. Efecto de la suplementación con harina de yacón y aceite de copaiba sobre el comportamiento productivo de pollos de carne en el periodo de 15 a 21 días de edad

\begin{tabular}{cccccc}
\hline Tratamientos $^{1}$ & $\begin{array}{c}\text { Peso inicial } \\
(\mathrm{g})\end{array}$ & $\begin{array}{c}\text { Peso final } \\
(\mathrm{g})\end{array}$ & $\begin{array}{c}\text { Ganancia de } \\
\text { peso } \\
(\mathrm{g} / \text { día) }\end{array}$ & $\begin{array}{c}\text { Consumo de } \\
\text { alimento } \\
(\mathrm{g} / \text { día) }\end{array}$ & $\begin{array}{c}\text { Conversión } \\
\text { alimenticia }\end{array}$ \\
\hline $\mathrm{T} 1$ & $539.7^{\mathrm{a}}$ & $1049.8^{\mathrm{a}}$ & $72.9^{\mathrm{a}}$ & $103.2^{\mathrm{a}}$ & $1.42^{\mathrm{a}}$ \\
$\mathrm{T} 2$ & $553.5^{\mathrm{a}}$ & $1070.2^{\mathrm{a}}$ & $73.8^{\mathrm{a}}$ & $98.1^{\mathrm{a}}$ & $1.33^{\mathrm{a}}$ \\
$\mathrm{T} 3$ & $554.5^{\mathrm{a}}$ & $1049.4^{\mathrm{a}}$ & $70.7^{\mathrm{a}}$ & $102.5^{\mathrm{a}}$ & $1.45^{\mathrm{a}}$ \\
$\mathrm{T} 4$ & $544.5^{\mathrm{a}}$ & $1054.5^{\mathrm{a}}$ & $72.9^{\mathrm{a}}$ & $95.9^{\mathrm{a}}$ & $1.32^{\mathrm{a}}$ \\
\hline
\end{tabular}

${ }^{1}$ T1: Grupo control (sin coccidiostato); T2: Grupo con coccidiostato; T3: Grupo con 0.25\% de harina de yacón (contenido de fructo oligosacáridos: $37.45 \mathrm{~g} F \mathrm{FS} / 100 \mathrm{~g}$ de harina de yacón); T4: Grupo con $0.150 \mathrm{ml}$ de aceite de copaiba/kg de alimento

${ }^{a}$ Superíndice similar dentro de columnas indica ausencia de diferencia estadística

en micrómetros $(\mu \mathrm{m})$. Asimismo, se determinó la relación altura de vellosidad y profundidad de cripta.

Se empleó un diseño experimental completamente al azar (Calzada, 1982) con cuatro tratamientos y tres repeticiones por tratamiento. El análisis de varianza se llevó a cabo usando el programa Statistical Analysis System (SAS, 1999) y la comparación de medias se realizó utilizando la prueba de Duncan (Duncan, 1955).

\section{Resultados y Discusión}

Los tratamientos dietarios no afectaron en forma significativa el comportamiento productivo de los pollos en el periodo 1 a 14 días de edad (Cuadro 3). Estos resultados guar- 
Cuadro 5. Número de ooquistes por gramo de heces de pollos de carne a los 21 días de edad, infectados experimentalmente con Eimerias en el día 14 de edad

\begin{tabular}{lc}
\hline Tratamientos & $\begin{array}{c}\text { Ooquistes } / \mathrm{g} \\
\text { de heces }\end{array}$ \\
\hline T1- Control & $12,067^{\mathrm{a}}$ \\
T2 - Con coccidiostato & $6,050^{\mathrm{a}}$ \\
T3 - Harina de yacón & $13,317^{\mathrm{a}}$ \\
T4 -Aceite de copaiba & $7,850^{\mathrm{a}}$ \\
\hline${ }^{\text {a }}$ Superíndice similar indica ausencia de \\
\multicolumn{2}{c}{ diferencia estadística $(\mathrm{p}<0.05)$}
\end{tabular}

dan relación con el estudio de Gonzales (2009) en pavos con harina de yacón, quien tampoco encontró diferencias estadísticas en el rendimiento productivo. Se ha indicado que la inclusión de FOS (4\%) como prebiótico en dietas de pollos de carne estimula un incremento en el crecimiento de bacterias y lactobacillus en el tracto gastrointestinal, promoviendo un aumento en la concentración de ácidos grasos de cadena corta y que estos últimos favorecen una mejora de la salud intestinal, resultando en una mejor respuesta productiva del animal (Xu et al., 2003); sin embargo, este comportamiento no fue observado y la diferencia podría atribuirse al menor nivel de harina de yacón utilizado en el presente estudio. Por otro lado, los resultados con el aceite de copaiba son similares a otros (Koiyama et al., 2013; Lopez et al., 2013), quienes tampoco encontraron diferencias significativas en relación con los grupos controles.

El comportamiento productivo de los animales entre los 15 y 21 días de edad estuvo condicionado a la respuesta al inóculo (desafío) de coccidia aplicado el día 14. En general, no hubo mortalidad ni aves postradas por efecto del desafío con coccidia. Los valores de ganancia de peso por día, consumo de alimento y la conversión alimenticia no fueron significativamente afectados por los tratamientos dietarios, aunque la conversión alimenticia de T2 y T4 fue ligeramente superior. La literatura científica indica que la infección por coccidias afecta la morfometría intestinal y como resultado de ello hay menos capacidad de digestión y absorción de nutrientes, comprometiendo así la conversión alimenticia (Adams et al. 1996; Allen, 1997; Patra et al., 2010).

El efecto protector del aceite de copaiba en cuadros de coccidiosis en aves no ha sido demostrado anteriormente; sin embargo, existe un antecedente de que este aceite ejerce un efecto protector en cuadros de lesiones (úlceras) gástricas en ratas (Arroyo et al., 2009). Además, existe considerable información sobre el potencial de productos fitogénicos y aceites esenciales, entre otros, como alternativas para el control de cuadros de coccidiosis aviar (Giannenas et al., 2003; Abbas et al., 2012; Küçükyilmaz et al., 2012; Luquetti et al., 2012). La tendencia de mejorar la conversión alimenticia en pollos que consumieron la dieta con aceite de copaiba debe ser estudiada en experimentos posteriores.

El número de ooquistes en las heces de pollos de carne infectados experimentalmente con Eimerias a los 14 días de edad se presenta en el Cuadro 5. No se encontró diferencia significativa entre tratamientos a pesar que las diferencias numéricas son considerables, dada la gran variabilidad de los resultados individuales. Sin embargo, se puede observar que los promedios de ooquistes por gramo de heces del grupo T3 (con harina de yacón) fue similar al grupo control (T1). El aceite de copaiba podría haber contribuido a la reducción del número de ooquistes a través de un proceso de ruptura (lisis) de la pared celular bacteriana (Santos et al., 2008); sin embargo, mayor investigación es necesaria.

Diversos experimentos han demostrado la efectividad de los coccidiostatos en reducir el número de ooquistes en heces y en la cama de las aves. Asimismo, algunos extractos herbales (Christaki et al., 2004), hongos (Willis et al., 2010) y aceites esenciales de 
Cuadro 6. Morfometría de los diferentes segmentos del intestino delgado (duodeno, yeyuno e íleon) en pollos infectados experimentalmente con Eimerias al $14^{\text {avo }}$ día de edad

\begin{tabular}{cccccc}
\hline $\begin{array}{c}\text { Porción } \\
\text { intestinal }\end{array}$ & Tratamiento $^{1}$ & $\begin{array}{c}\text { Altura de } \\
\text { vellosidades } \\
(\mathrm{AV})(\mu \mathrm{m})\end{array}$ & $\begin{array}{c}\text { Profundidad } \\
\text { de cripta } \\
(\mathrm{PC})(\mu \mathrm{m})\end{array}$ & $\begin{array}{c}\text { Células } \\
\text { caliciformes } \\
(\mathrm{CC})(\mathrm{n})\end{array}$ & $\begin{array}{c}\text { Relación } \\
\text { AV:PC }\end{array}$ \\
\hline Duodeno & & & & & \\
& $\mathrm{T} 1$ & $956.6^{\mathrm{a}}$ & $193.4^{\mathrm{b}}$ & $141.8^{\mathrm{a}}$ & $5.48^{\mathrm{a}}$ \\
& $\mathrm{T} 2$ & $1004.1^{\mathrm{a}}$ & $239.1^{\mathrm{ab}}$ & $125.3^{\mathrm{a}}$ & $4.56^{\mathrm{a}}$ \\
& $\mathrm{T} 3$ & $986.5^{\mathrm{a}}$ & $182.8^{\mathrm{b}}$ & $143.0^{\mathrm{a}}$ & $5.64^{\mathrm{a}}$ \\
& $\mathrm{T} 4$ & $1030.9^{\mathrm{a}}$ & $257.2^{\mathrm{a}}$ & $122.7^{\mathrm{a}}$ & $4.06^{\mathrm{a}}$
\end{tabular}

Yeyuno

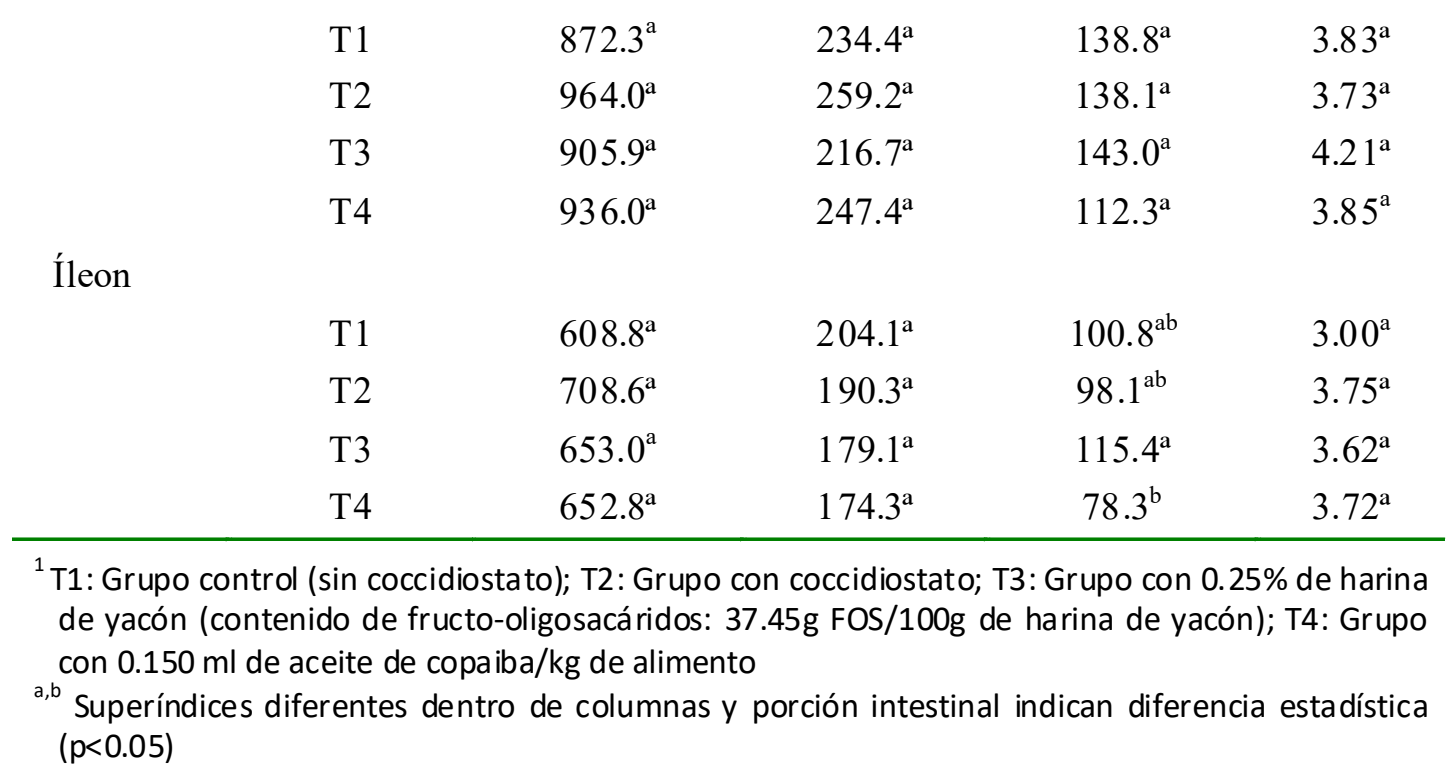

orégano (Giannenas et al., 2003; Major et al., 2011; Martínez, 2012) han demostrado tener un efecto sobre la infección por coccidias.

En el presente trabajo se observó heces con sangre y restos de mucosas, un rasgo característico de la coccidiosis. A la necropsia, se encontró un contenido lechoso en los intestinos debido a la formación de ooquistes y, además, se observaron lesiones intestinales que son compatibles con presencia de E. acervulina y E. máxima
En el Cuadro 6 se presenta el efecto conjunto de la infección experimental y los tratamientos dietarios sobre la morfometría (altura de vellosidad [AV], profundidad de cripta [PC], número de células caliciformes $[C C])$ y la relación altura de vellosidad con profundidad de cripta [AV:PC] según la porción de intestino delgado (duodeno, yeyuno e íleon).

Los valores promedios de $\mathrm{AV}$ y de la relación AV: PC del duodeno, yeyuno e íleon no fueron influenciados por los tratamientos 
dietarios. Tampoco la PC en yeyuno e íleon ni el número de $\mathrm{CC}$ en duodeno y yeyuno. No obstante, la PC en el duodeno y las CC en el íleon fueron significativamente influenciadas por los tratamientos dietarios $(p<0.05)$. Los mayores valores de PC duodenal correspondieron a los grupos T4 y T2, y el valor más bajo en el número de $\mathrm{CC}$ en el íleon correspondió a los grupos T4 y T2.

En general, se puede observar que la altura de las vellosidades va decreciendo según los segmentos del intestino. Martínez (2012) reporta reducciones de hasta $30 \%$ en cada sección del intestino delgado respecto al anterior.

La mayor profundidad de cripta en el duodeno de animales que recibieron el tratamiento con aceite de copaiba podría ser debida a su efecto cicatrizante (Arroyo et al., 2009). Este efecto radicaría en la naturaleza compleja de la mezcla de sesquiterpeno, diterpeno y cariofileno existente en su composición (Arroyo et al., 2009; Leite et al., 2013). El aumento de la profundidad de las criptas podría ser consecuencia de un aumento de la diseminación de la superficie de la vellosidad para generar una mayor renovación celular en la zona apical (Oetting et al., 2006). Por lo tanto, el presente estudio estaría confirmando el efecto regenerativo a nivel celular del aceite de copaiba sobre la mucosa del duodeno, indicando un incremento en la actividad mitótica en la cripta, a fin de mantener un adecuado recambio celular en el epitelio del duodeno (Pluske et al., 1997).

Las CC tienen como función producir mucus que sirve como lubricación y protección de la mucosa intestinal; sin embargo, la cantidad de mucus producido en un determinado segmento del intestino delgado está en relación directa con la presencia de microorganismos patógenos en dicho segmento (Podolsky et al., 1993; Martínez, 2012). En el presente estudio, las aves tratadas con aceite de copaiba (T4) presentaron el menor número de $\mathrm{CC}$ en el íleon, seguidas de las aves del grupo control. Este resultado podría significar que el estímulo o la necesidad de producir mayor cantidad de mucus en estas aves era menor debido a la baja presencia de coccidias ante la acción del aceite de copaiba o del coccidiostato en la dieta. Zea (2011) encontró en pollos de carne un mayor número de $\mathrm{CC}$ en aves que consumieron dietas sin antibióticos, en comparación con aves alimentadas con dietas suplementadas con antibióticos.

\section{Conclusiones}

- Los tratamientos dietarios suplementados con harina de yacón y aceite de copaiba no afectaron la respuesta productiva de pollos de carne en la fase de 1 a 14 días de edad ni en la fase de posinoculación experimental con Eimerias (15 a 21 días de edad).

- La suplementación de aceite de copaiba $(0.150 \mathrm{ml} / \mathrm{kg}$ de alimento) resultó en una mayor profundidad de cripta y menor de número de células caliciformes en el duodeno e íleon de los animales.

- La inclusión de harina de yacón, como fuente de fructo-oligosacáridos $(0.25 \%)$ en la dieta, no mostró acción protectora del intestino delgado en animales infectados experimentalmente con Eimerias.

\section{Literatura Citada}

1. Abbas RZ, Colwell DD, Gilleard J. 2012. Botanicals: an alternative approach for the control of avian coccidiosis. World Poultry Sci J 68: 203215. doi: $10.1017 / \mathrm{S} 0043933912000268$

2. Adams BY, Vahl HA, Veldman A. 1996. Interaction between nutrition and Eimeria acervulina infection in broiler chickens: development of an experimental infection mode. Br J Nutr 75: 867873. doi: 10.1079/BJN19960193

3. Allen PC, Lydon J, Danforth H. 1997. Effects of components of Artemisia annua on coccidian infections in chickens. Poultry Sci 76: 1156-1163. 
4. Arroyo J, Almora Y, Quino M, Martínez J, Condorhaman M, Flores M, Bonilla P. 2009. Efecto citoprotector y antisecretor del aceite de Copaifera officinalis en lesiones gástricas inducidas en ratas. An Fac Med 70: 89-96. doi: 10.15381/anales.v70i2.955

5. Batista de Oliveira P, Murakami AE, De Moraes Garcia, ER, Macari M, Scapinello C. 2000. Influence of antinutritional factors of leucaena (Leucaena leucocephala and Leucaena cunningan) and pigeous bean (Cajanus cajan) on the intestinal epithelium and performance of broiler chickens. Rev Bras Zootec 29: 17591769. doi: 10.1590/S1516-35982000000600024

6. Calzada BJ. 1982. Métodos estadísticos para la investigación. $5^{\mathrm{a}}$ ed. Lima, Perú: Ed Jurídica 644 p.

7. Christaki E, Florou-Paneri P, Gianneras I, Papazahariadou $M$, Botsouglou N, et al. 2004. Effect of a mixture of herbal extracts on broiler chickens infected with Eimeria tenella. Anim Res 53: 137-144. doi: 10.1051/ animres:2004006

8. Cobb-Vantres. 2002. Cobb 500 Broiler performance and nutrition supplement. [Internet]. Available in: http:// http:// www.cobb-vantress.com/docs/defaults o u r c e / c o b b - $500-\mathrm{guides} /$ Cobb500_Broiler_Performance_ And_Nutrition_Supplement.pdf

9. Duncan DB. 1955. Multiple range a multiple F test. Biometrics 1: 1-42.

10. Farrant J. 2001. Ministers knock down six anticoccidials. Poultry World 155: 5.

11. Giannenas I, Florou-Paneri $P$, Papazahariadou M, Christaki E, Botsoglou N.S, Spais AB. 2003. Dietary oregano essential oil supplementation on performance of broilers challenged with Eimeria tenella. Arch Anim Nutr 57: 99-106. doi: 10.1080/ 0003942031000107299

12. Gonzales HM. 2009. Evaluación de la harina de yacón (Smallanthus sonchifolius) como prebiótico en dietas de pavos de engorde. Tesis de Médico Veterinario. Lima: Univ Nacional Mayor de San Marcos. $81 \mathrm{p}$.

13. Koiyama NTG, Rosa AP, Boemo LS, Padilha MTS, Scher A, Branco T, Forgiarini J. 2013. Performance assessment of broiler chickens supplemented with copaiba oil-resin. J Anim Prod Adv 3: 311-317.

14. Küçükyilmaz K, Bozkurt M, Selek N, Güven E, Eren H, Atasever A, Bintas $E$, et al. 2012. Effects of vaccination against coccidiosis, with and without a specific herbal essential oil blend, on performance, oocyst excretion and serum IBD titers of broilers reared on litter. Italian J Anim Sci 11(1). doi: 10.4081/ ijas.2012.e1

15. Leite NF, Sobral-Souza CE, Albuquerque RS, Brito DIV, Lavor A, Alencar L, Tintino SR, et al. 2013. Actividad antiparasitaria in vitro citotóxica de cariofileno y eugenol contra Trypanosoma cruzi y Leishmania brasiliensis. Rev Cubana Plant Med 18: 522-528.

16. Lopez CA, De Souza Lima KR, Manno MC, Barbosa F, Pereira de Souza V, Fernandes DL. 2013. Effect of copaiba essential oil on broiler chickens' performance. Acta Sci Anim Sci 35: 145-151. doi: 10.4025/actascianimsci.v35i2.15376

17. Luquetti BC, Furla RL, Alarcon MFF, Macar M. 2012. Saccharomyces cerevisiae cell wall dietary supplementation on the performance and intestinal mucosa development and integrity of broiler chickens vaccinated against coccidiosis. Rev Braz Cienc Avic 14: 71-158. doi: 10.1590/S1516635X2012000200002

18. Major P, Revajora V, Levkut M, Sevcikova Z, Spisakova V, Faixova Z, Levkutova $M$, et al. 2011. Intestinal mucin dynamic and leukocytic responses of chickens infected with Eimeria acervulina and fed oregano supplemented diet. Acta Vet Brno 80: 147-156. doi: 10.2754/avb201180020147 
19. Martínez DA. 2012. Evaluación de un producto a base de aceite esencial de orégano sobre la integridad intestinal, la capacidad de absorción de nutrientes y el comportamiento productivo de pollos de carne. Tesis de Magíster. Lima: Univ Nacional Agraria La Molina. 368 p.

20. Oetting LL, Utiyama CE. 2006. Efeitos de extracts vegetais e antimicrobianos sobre a digestibilidade aparente, o desempenho, a morfometria dos orgaos e a histologia intestinal de leitoes recem-desmamados. Rev Bras Zootec 35: 1389-1397. doi: 10.1590/ S1516-35982006000500019

21. Patra G, Ali MA, Chanu KV, Jonathan $L$, Joy LK, Prava M, Ravindran $R$, et al. 2010. PCR bases diagnosis of Eimeria tenella infection in broiler chicken. Int J Poultry Sci 9: 813-818. doi: 10.3923/ijps.2010.813.818

22. Pluske JR, Williams IH, Aherne FX. 1997. Maintenance of villous height and crypt depth in piglets by providing continuous nutrition after weaning. Anim Sci 62: 131-144. doi: 10.1017/ S1357729800014417

23. Podolsky DK, Lynch-Devaney K, Stow $J$, Oates P, Murgue B, DeBeaumont $M$, et al. 1993. Identification of human intestinal trefoil factor. J Biol Chem 268: 6694-6702.

24. Santos AO, Ueda-Nakamura T, Dias Filho BP, Veiga VF, Pinto $A C$, Nakamura $C V$. 2008. Antimicrobial activity of Brazilian copaiba oils obtained from different species of the Copaifera genus. Mem Inst Oswaldo Cruz 103: 277 281. doi: $10.1590 / \mathrm{S} 0074-0276200800$ 5000015

25. SAS Institute. 1999. Statistical analysis system. User's Guide Statistics. $8^{\text {th }}$ ed. Cary. North Carolina, USA: SAS Institute Inc. $965 \mathrm{p}$.

26. Willis WL, Isikhuemhen OS, Minor RC, Hurley S, Ohimain EI. 2010. Comparing the feeding of fungus myceliated grain with other anticoccidial control measures on oocyst excretion of Eimeria challenged broilers. Int J Poultry Sci 9: 648-651.

27. Хи RZ, Hu HC, Xia SM, Zhan XA, Wang QM. 2003. Effects of dietary fructooligosaccharide on digestive enzyme activities, intestinal microflora and morphology of male broilers. Poultry Sci 82: 1030-1036. doi: 10.1093/ps/ 82.6.1030

28. Zahid R. 2008. Studies on the development of resistance in Eimeria tenella field isolates against commonly used anticoccidials. PhD Thesis. Pakistan: University of Agriculture Faisalabad. [Internet]. Available in: http:/ /prr.hec.gov.pk/thesis/2330.pdf

29. Zea OA. 2011. Efecto de la suplementación con diferentes fuentes de cobre sobre el comportamiento productivo, morfometría intestinal y el nivel de cobre hepático en pollos de carne. Tesis de Magíster. Lima: Univ Nacional Agraria La Molina. 103 p. 